\title{
Overview of 10 inch Diameter HTPB Hybrid Motor Testing with Liquid Oxygen at Stennis Space Center
}

\author{
Timothy E. Knowles ${ }^{1}$ and Darren Kearney ${ }^{2}$ \\ Lockheed Martin Space Systems Company, New Orleans, Louisiana,70129 \\ Ryan Roberts ${ }^{3}$ \\ National Aeronautics and Space Administration, Stennis Space Center, Mississippi
}

$\begin{array}{ll} & \\ \text { FRT } & =\text { Facility readiness tests } \\ \text { GN2 } & =\text { Gaseous Nitrogen } \\ \text { GO2 } & =\text { Gaseous Oxygen } \\ \text { HTPB } & =\text { Hydroxyl Terminated Polybutadiene } \\ \text { HTTP } & =\text { Hybrid Technology Test Program } \\ \text { klbf } & =\text { thousand pounds force } \\ \text { Lb } & =\text { pounds } \\ \text { Lbf } & =\text { pounds force } \\ \text { lbm/s } & =\text { pounds mass per second } \\ \text { LO2 } & =\text { Liquid Oxygen } \\ \text { P\&ID } & =\text { Piping and instrumentation diagram } \\ \text { PLC } & =\text { Programmable Logic Controller } \\ \text { psi } & =\text { pounds per square inch } \\ \text { SSC } & =\text { Stennis Space Center } \\ \text { STE } & =\text { Special Test Equipment } \\ \text { TCC } & =\text { Test Control Center } \\ \text { TEB } & =\text { Terminating Electrical Box }\end{array}$

\section{Introduction}

$\mathrm{T}_{\mathrm{s}}$

further explore the operation of hybrid rocket motors and to demonstrate the performance characteristics of the motor design Lockheed Martin funded research on a series of 10 inch diameter hybrid motors that produce less than $10 \mathrm{klbf}$ sea level thrust. This test series was given the name "Hybrid Technology Test Program." These motors were fired in the existing test stand at the SSC E-3 complex Cell 1. The fuel and oxidizer for these 10 inch diameter motors are HTPB and LO2, respectively. The original goal of the testing was to verify that the predicted performance matched the actual performance of these 10 inch motors (ref. figure 1) and then confirm that the motors performed acceptably. For this element of testing horizontally fired hybrid motors will be tested using $\mathrm{LO} 2$ supplied from the existing facility 100 gallon LO2 tank that is pressurized with facility GN2. The thrust produced by the motor will be measured by a Lockheed Martin supplied load cell.

\footnotetext{
${ }^{1}$ Principal Investigator, Hybrid Propulsion Systems, Lockheed Martin Space Systems Company, Michoud Operations, Program Management and Advanced Programs Dept 4500, Michoud Assembly Facility, P.O. Box 29304, New Orleans, LA 70189-0304, Member AIAA.

${ }^{2}$ Propulsion Analyst, Propulsion Analysis Department 4160, AIAA Member.

${ }^{3}$ Aerospace Technologist - Mechanical Experimental Equipment, Mechanical Test Operations, Stennis Space Center 39529, Mail Stop VA20S
}

American Institute of Aeronautics and Astronautics 


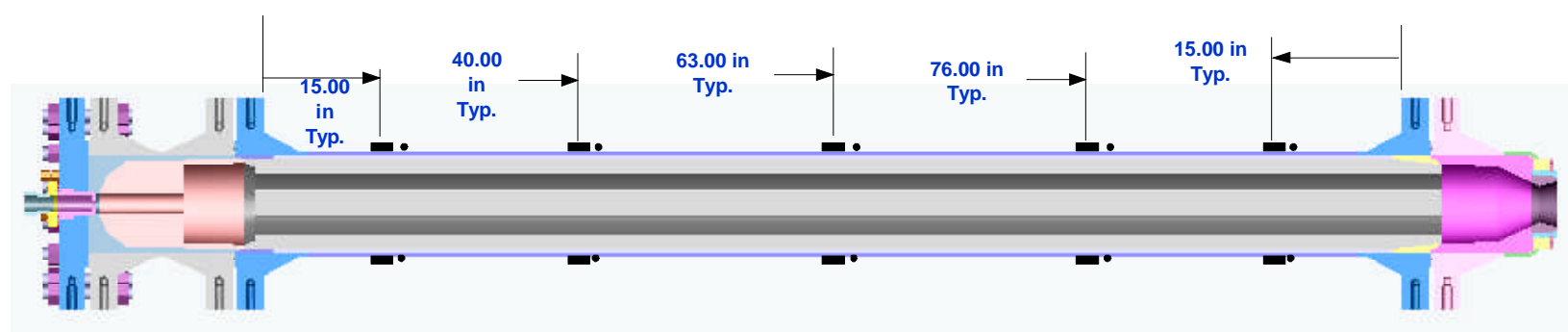

Figure 1 - Cross-section of the 10 inch diameter hybrid rocket motor with strain gage and thermocouple location indicated.

\section{The Test Facility and Test Preparations}

The Stennis Space Center E3 Cell 1 facility was utilized to execute the Lockheed Martin Michoud Operations Hybrid Technology Test Program (HTTP). After specific test requirements were communicated to SSC, necessary facility modifications were performed, STE tubing, structural, and electrical systems were designed and fabricated, individual systems were checked for functionality, activation testing was performed to verify that the systems satisfied HTTP requirements, and the tests were executed.

P\&ID's were generated to depict overall layouts of the necessary facility, STE and test article systems and to translate specific HTTP requirements to the SSC design and test teams. The P\&ID's specified the fluid and pressure sources, clean levels, valves, orifices, instrumentation, tubing sizes, and all other components and related component information necessary for the systems to be fabricated in order to execute the proposed testing.

Mechanical Buildup - After P\&ID's were released, necessary facility modifications were initiated. The STE tubing systems to connect the facility and test article interfaces were fabricated. Valves, filters, control orifices, precalibrated pressure and temperature instrumentation, tubing systems, and other components were fabricated, cleaned, installed and structurally supported to ground as necessary. In addition the HTTP test article support and hold-down structures and the thrust resisting structures were fabricated and anchored to the facility.

Electrical Buildup and Checkout - A list of all of the instrumentation and control valves that needed to be remotely operated from the E3 TCC was generated from the P\&ID's. Wire connections were fabricated from pre-assembled channels in a TEB located near the E3 cell 1 facility to the individual HTTP control valves to allow command signal and position control and feedback. The TEB channels were already connected to the PLC housed in the Signal Conditioning Building located near the test stands. A controls engineer built control screens and programmed Wonder Ware TM Operator Interface software to interface with the PLC to be able to control the systems remotely from the TCC. During the checkout phase, valves were remotely cycled using the control screens to verify proper operation and position feedback to the TCC screens.

Mechanical Checkout - After all of the controls and instrumentation components were proven operational, the GO2, GN2, and LO2 systems were externally leak checked at ambient temperature up to their respective maximum allowable pressures. In addition, the $\mathrm{LO} 2$ system was externally leak checked to its maximum allowable pressure at cryogenic temperatures. At this point all control valves that were required to isolate fluid pressure during execution of the test sequence were internally leak checked at ambient and cryogenic temperatures by supplying pressure to the appropriate side of the valve and monitoring the pressure on the opposite side.

Activation Testing - After all mechanical and electrical systems were checked for operational adequacy, activation of the controls and instrumentation systems was conducted to verify that the specific HTTP requirements could be met. The PLC control system was designed to provide real time control of propellant transfers, tank pressurizations, test article conditioning, ignition, and propellant flows and to automatically cycle control valves

American Institute of Aeronautics and Astronautics 
though a series of predetermined states specified by the HTTP requirements. Data from the control system was tagged with IRIG and stored for real-time display and post-test analysis. During electrical activation and with no fluids or pressure in the systems, the control system was utilized to cycle all system components and to verify that the HTTP run sequences and emergency shutdown sequences could be executed. Iterative electrical activation tests were performed while analyzing controls and feedback data between each run to verify that all electrical, and low speed and high speed data acquisition systems operated and responded as needed to satisfy requirements.

Several cold flow tests were performed in order to determine LO2 tank ullage volume and pressurization rate requirements, to verify oxidizer flow rates, to verify purge flow adequacy, and to investigate $\mathrm{LO} 2$ and GO2 system control valve timing. A high speed video camera activated by the control system to establish time correlation to the valve command times was used to gather command-to-flow delay times.

Several ignition system activation tests were performed using the control system to operate the actual ignition system components that would be used for hot fire testing. The hybrid motor igniters were connected to the power source through electrical relays and the HTTP sequence was executed to burn the igniters in air. Again, the high speed video camera was used during these activation tests to gather command-to-ignition delay times.

The command-to-action delay times from the oxidizer and ignition system activation tests were used to develop the actual HTTP hot fire sequence.

Test Article Installation - The HTTP hybrid motor test articles were weighed and lifted with an overhead crane and installed and secured into the STE test article support structure. The oxidizer and test article pressure and temperature interface connections were made, and each test article was aligned with the facility thrust takeout structure. A test article leak check was performed to verify all interface connections and then the test article nozzle was installed.

Testing - On the day of a hot fire test, pressure in all systems was relieved, instrumentation calibrations were performed, and all controlled valves were checked for functionality. At this point, the hot fire sequence was used in a series of FRT's which executed the sequence and all emergency and shutdown situations. Data from these FRT's was analyzed to ensure that the systems were operating and responding properly. At this point authority to proceed was given to the test team, and hot fire testing procedures were started. After the LO2 system was filled and temperature conditioned, calibrations were performed on the thrust measurement system. Igniters were then connected, systems were remotely pressurized and sequenced hot fire of the HTTP test articles was accomplished.

\section{The Motor Fabrication}

Two hybrid motors were cast in a 10-inch diameter Schedule 40, carbon steel pipe with bolt-on forward and aft domes containing the staged combustion heaters and the post combustion chamber, respectively. Each test article will contain a maximum of $250 \mathrm{lb}$ of cured HTPB fuel. The fuel grains were of Double-D configuration. The Double-D configuration refers to a two port fuel grain where the cross-section of the port is a 2 inch wide segment of a 6 inch diameter circle (looks like a skinny letter D) with these ports mirror imaged back to back. The motor and associated components are designed for an operating pressure of 500 psi, a maximum sea level thrust of 6500 lbf, and burn duration of 25 seconds (ref. figure 2). This design will incorporate the Michoud Operations staged combustion heater system that uses electric igniters and a small gaseous oxygen flow throughout the test. The stub nozzles were made from ATJ graphite with a throat diameter of 3.7 inches and an exit of 4.7 inches for an expansion ratio of 1.61. The fore and aft domes are lined with an insulation cast from phenolic resin bonded into the case with a high temperature adhesive. The center section of the motor case (the fuel grain) of the first test motor was insulated with medium grain extruded graphite bonded into the case with a high temperature adhesive and was cast with a room temperature cured formulation of HTPB. The second motor was cast with an elevated temperature cured formulation of HTPB in an uninsulated case. The motors were designed for an LO2 flow rate of $19 \mathrm{lbm} / \mathrm{s}$ (ref. figure 3) and also require approximately $1.5 \mathrm{lbm} / \mathrm{s}$ of gaseous oxygen delivered to a total of 4 separate staged combustion heaters at a pressure of at least $900 \mathrm{psig}$ upstream of the regulating orifice. The motor case was tapped for pressure measurements in the chambers before and after the fuel grains. The motors were also instrumented with strain gages and thermocouples and on the second motor, accelerometers.

American Institute of Aeronautics and Astronautics 


\section{The Results \& Discussion}

\section{A. Test \#1 - HTT-001}

The first test was run for 12.5 seconds or about half the potential motor duration. This would allow measurement of the remaining web thickness and calculate the fuel remaining in the motor to get an indication of the fuel regression rate and project the full burn duration. The expectation was that the measurements from the first test would confirm the expected regression rate and other performance characteristics.

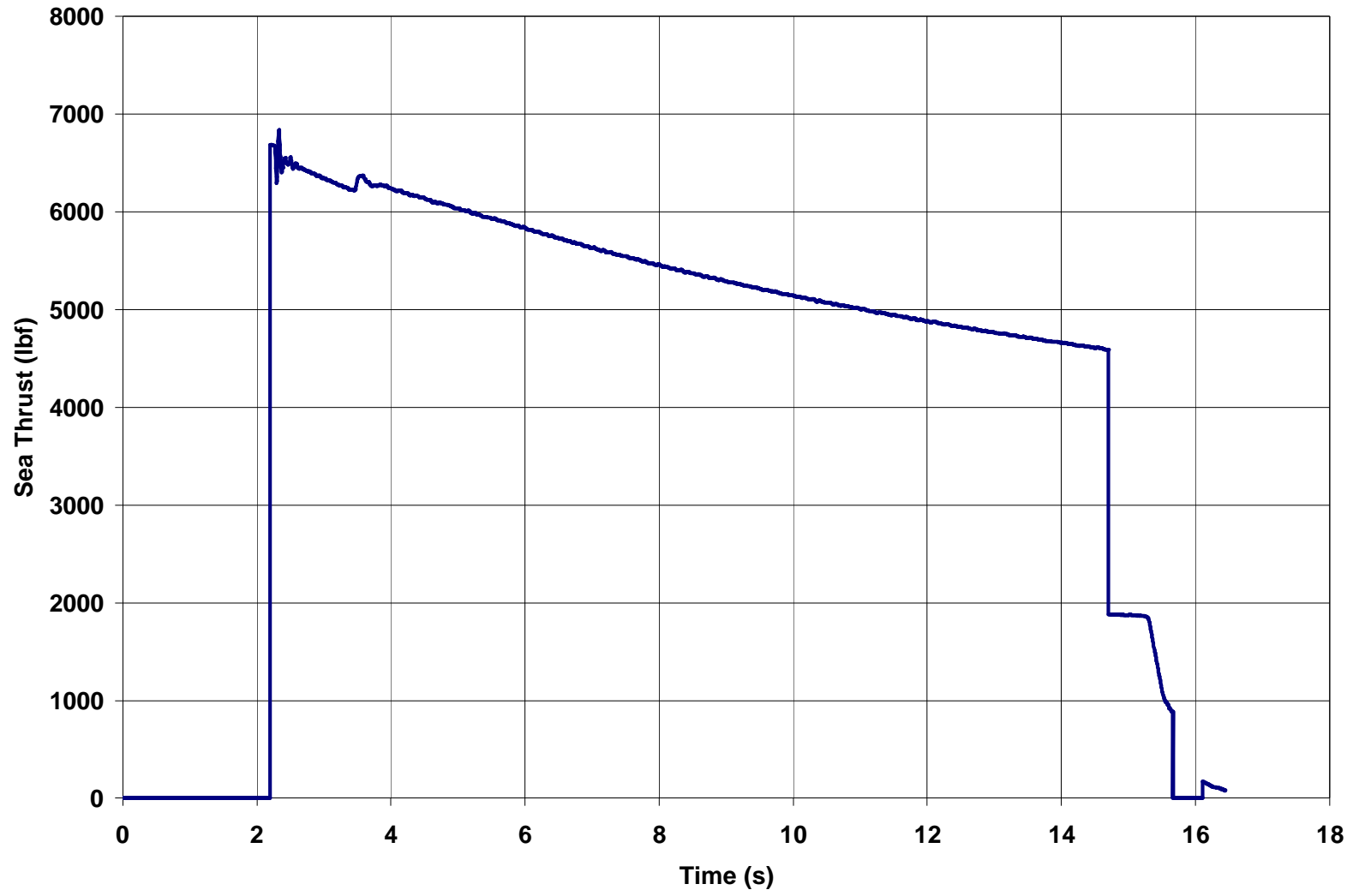

Figure 2 - Predicted Sea Level thrust for the HTT-01 test of 10 inch HTPB Double "D" Hybrid Motor with a nozzle expansion ratio of $6.8: 1$ and firing duration of 12.5 seconds 


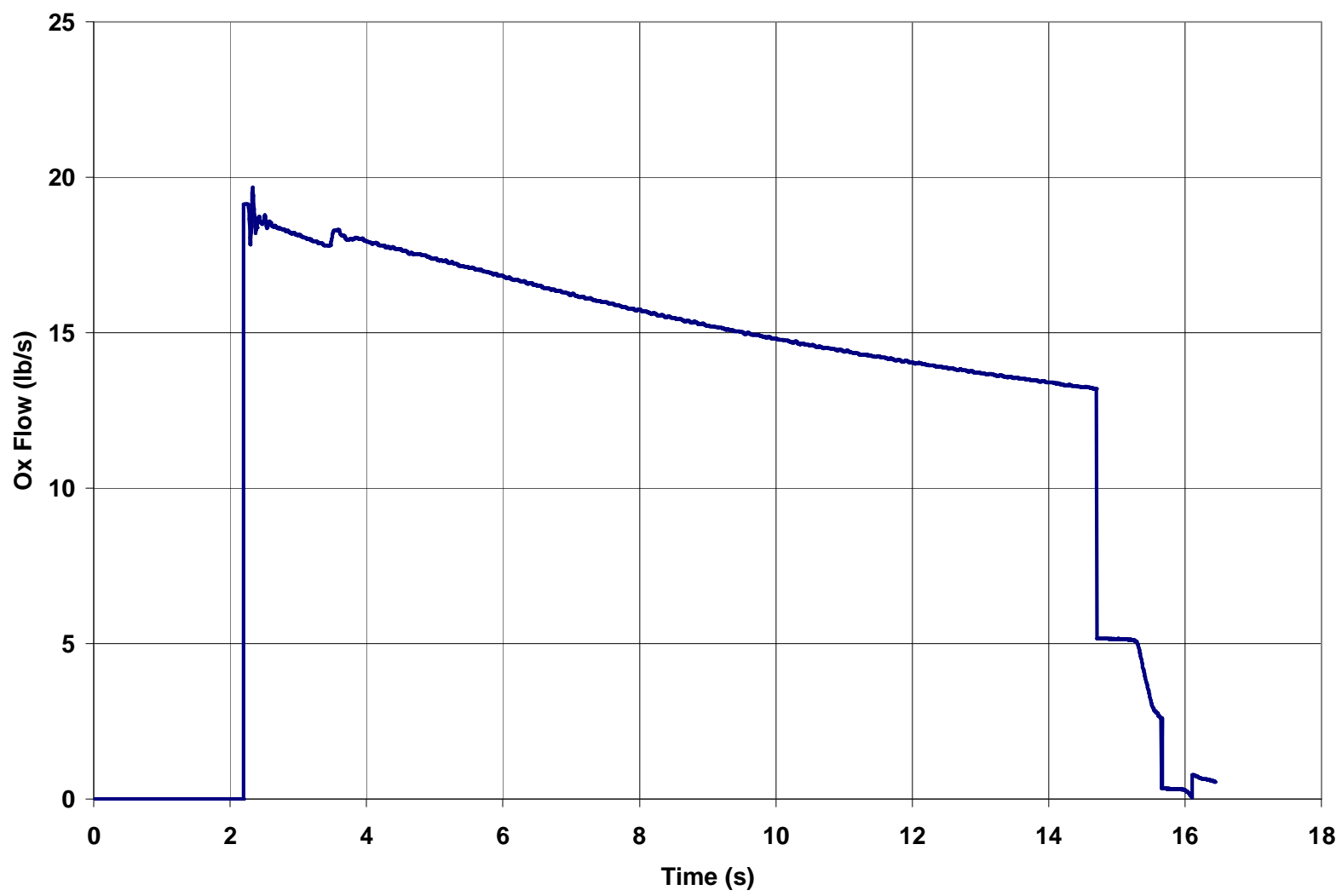

Figure 3 - Predicted LO2 Flow Rate for the HTT-01 test of the 10 inch HTPB Double "D" Hybrid Motor

Prior to the first test, flow and timing tests were performed using liquid nitrogen and gaseous nitrogen to simulate the liquid oxygen and gaseous oxygen that would be required in the test firing. A high speed digital camera was setup so that the igniters, liquid and gas flow could all be seen in the same frame. The countdown sequence was performed and the critical events filmed. The film was reviewed at slow speed to verify that the actual events happened in the appropriate sequence with the proper lead/lag for successful motor ignition. The flow rates and pressures for the fluids were also measured or calculated to confirm the proper injection conditions.

As previously indicated the first test was to be partial duration so that measurements of the remaining fuel could be made and compared to analytically predicted residuals. The facility was prepared and the test was run on December $5^{\text {th }}, 2003$. The test was run for the planned burn duration of 12.5 seconds. At 7.4 seconds into the burn there was a significant change in the sound of the motor and the exhaust plume began to flicker, at the same time the chamber pressure and thrust spiked and then dropped back to a level lower than previous trend and the predictions (ref. figures 3 and 4). The remaining seconds of burn time were completed with lower and erratic performance. After the motor cooled and personnel were allowed back out to the test stand a visual inspection of the motor through the nozzle opening was performed. Looking through the nozzle it was obvious that a large portion of the fuel web had torn loose and had been ejected through the nozzle, ref. figure 5 .

American Institute of Aeronautics and Astronautics 


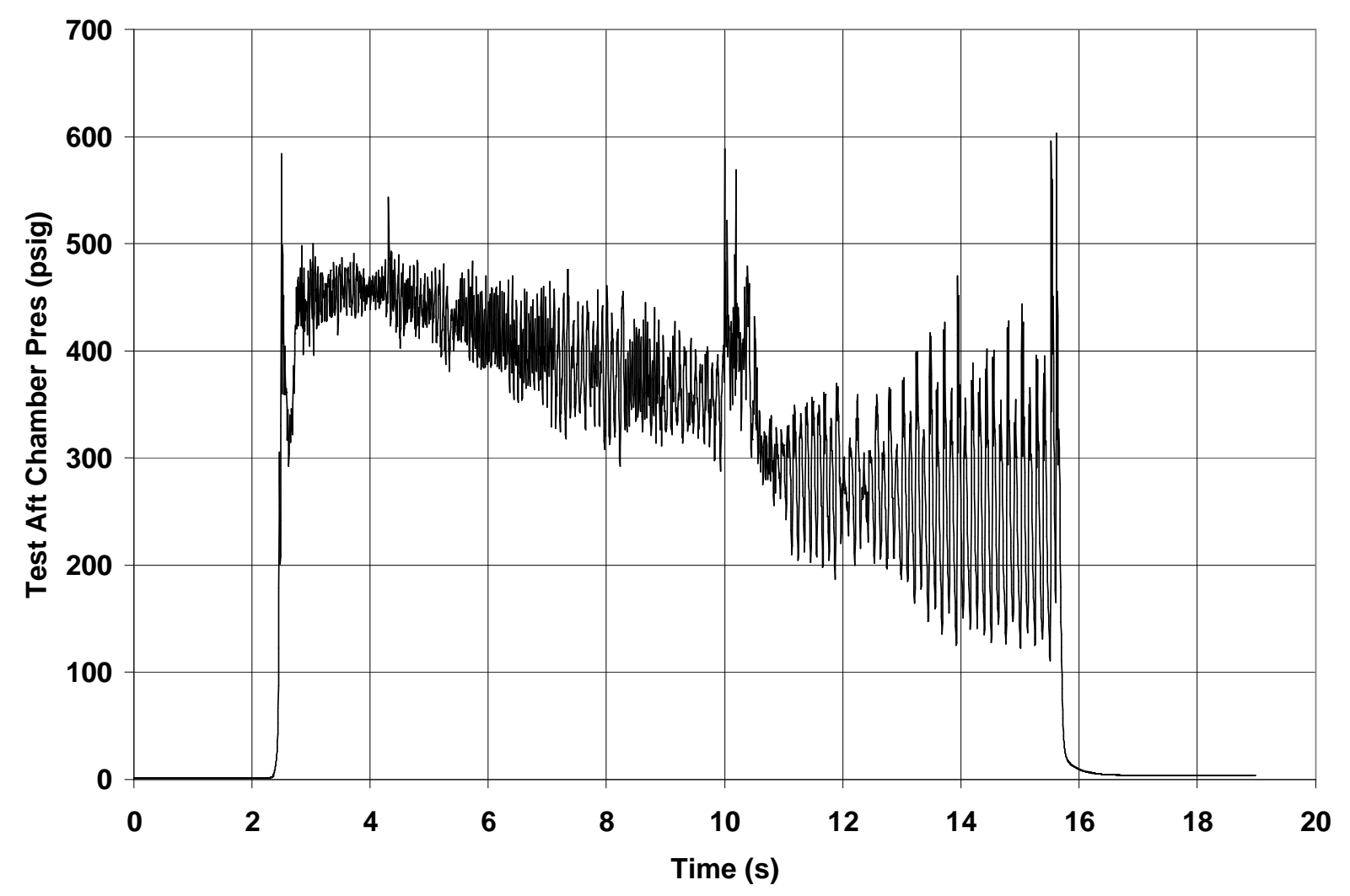

Figure 4 - Actual HTT-01 Forward Chamber Pressure vs. Time Profile

Figure 5 - The HTT-01 Post Test the fuel grain as viewed through the nozzle 


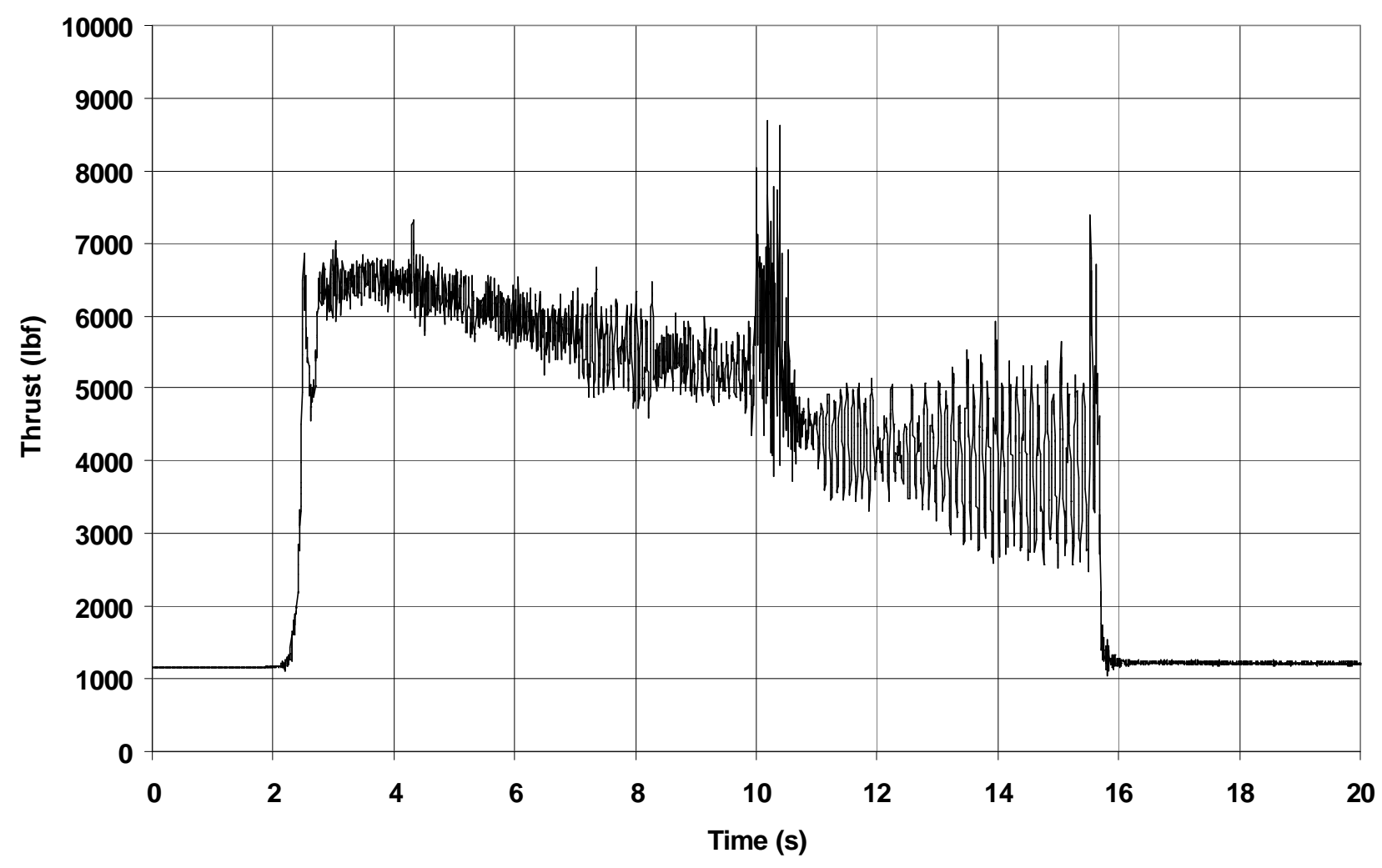

Figure 6 - The actual HTT-01 thrust vs. time plot

In addition to the damage to the fuel web it was detected that the GO2 injectors were damaged. It appears that these injectors were not adequately protected from the severe environment of the head end of the motor. The GO2 injectors provide the oxidizer for motor ignition and for the staged combustion heater motors. It is the output of these heater motors that enable the motor to run stably at high fluxes.

\section{B. The Cause of the Failure}

Three possible causes were identified for the failure either independently or together. The possible causes of the failure are, first, the low tensile strength of this blend of HTPB, second, a convergence of a motor vibration mode with the web natural frequency and finally, the high port to port delta pressure due to the GO2 injector damage. Either or both of the later two possible causes could have interacted with the first to cause the failure. To avoid these possible interactions a program was executed to develop a stronger fuel that would still regress at a rate similar to or better than the room temperature curing fuel that was cast in the first motor. To better protect the $\mathrm{GO} 2$ injectors from severe environment of the heat end of the motor the installation was redesigned with closer tolerances and to present the hot gases a more torturous path to reach the side of the injector. Inadequate data is available to redesign the motor to preclude the convergence of the motor vibrations and the web natural frequency during a full duration firing, therefore the next tests duration was shorter than the time expected for the convergence. The motor and test stand had accelerometers attached to monitor the vibration environment.

\section{The Second Test - HTT-002}

The HTT-02 motor is almost identical to the HTT-01 with just a few exceptions. The GO2 injector installation

American Institute of Aeronautics and Astronautics 
was revised, the room temperature curing fuel was replaced with an elevated temperature curing fuel with higher strength, and the graphite insulation in the motor case was eliminated as installation process for it is incompatible with the elevated temperature cure fuel process.

The goals of the second test were to demonstrate the resolution of the HTT-01 problems. The fuel grain must remain intact for the duration of the test. The injectors must also remain intact. The accelerometers, strain gages and other test instrumentation need to provide good data for post test analysis. Because of the long stand down of the test stand the flow and timing tests were again performed using liquid nitrogen and gaseous nitrogen to simulate the liquid oxygen and gaseous oxygen. The LOX flow was reduced to a maximum of 15 pounds per second to compensate for the slightly higher regression rate expected for the new fuel formulation. During the flow and time test this lower flow rate and all countdown times were confirmed.

As previous indicated the HTT-02 test was of partial duration terminating prior to predicted web failure to ensure an accurate post-test measurement of fuel depletion. The facility was prepared and the test was run on May $19^{\text {th }}, 2004$ (ref. figure 7). The test was conducted for the planned duration of 7.5 second motor burn time. The motor was shutdown normally and a quick inspection revealed that fuel web was intact. The test goals were met as the fuel web remained intact the injectors were not damaged and we got good data from all measurements.

\section{Post test analysis}

The web thickness was measured at the ends of the web (ref. figures 8 and 9) and the motor was weighed to establish the average regression rate. The measurements at the ends of the web overestimate the regression due to entrance and exit effects. Weighing the motor provided a better indication of the average regression of 61 mils per second. The motor experienced a chamber pressure oscillation mid-way into the burn. In reviewing the HTT-01 data the chamber pressure oscillation was attributed to the fracture of the fuel grain web but because the web in this case was still intact the oscillation must have a different cause.

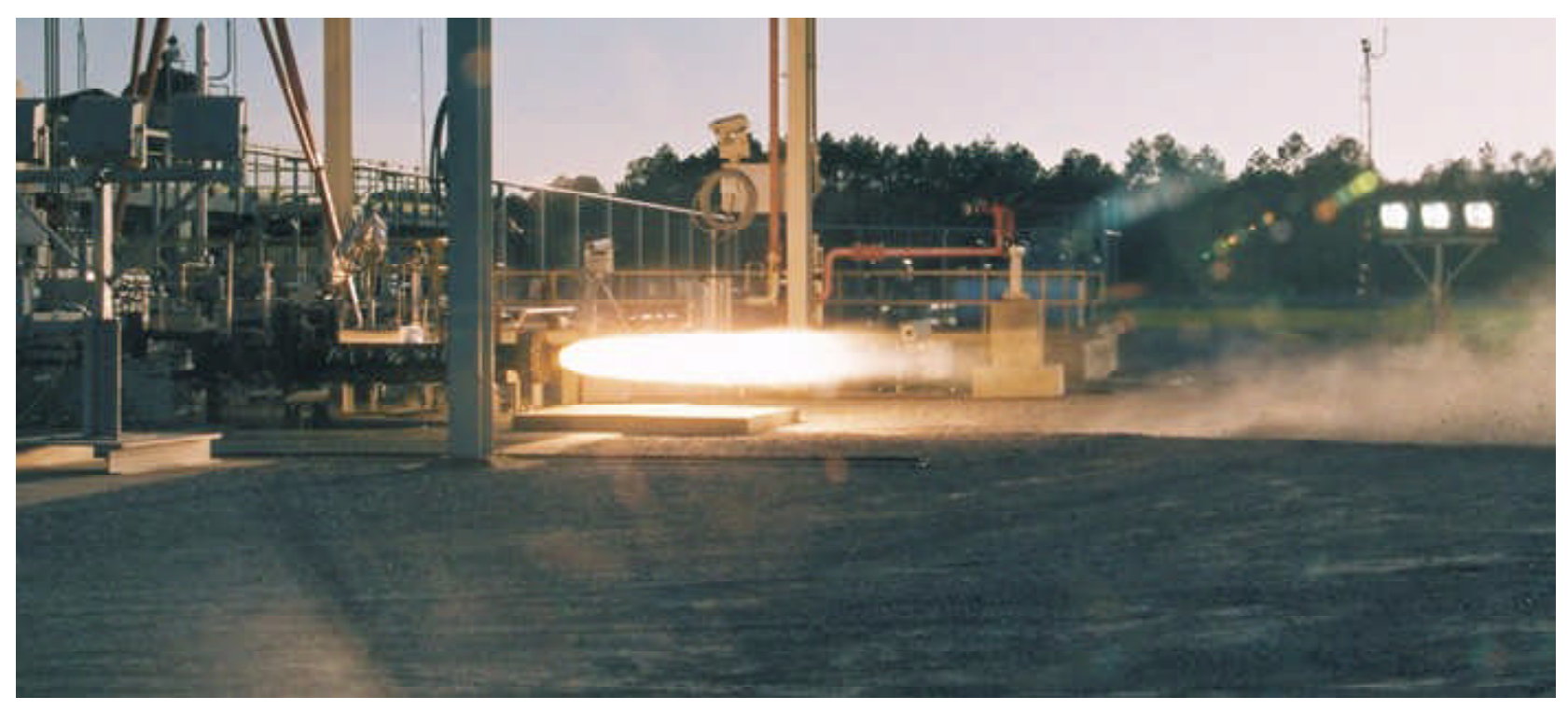

Figure 6 - Picture of the HTT-02 Motor during test 


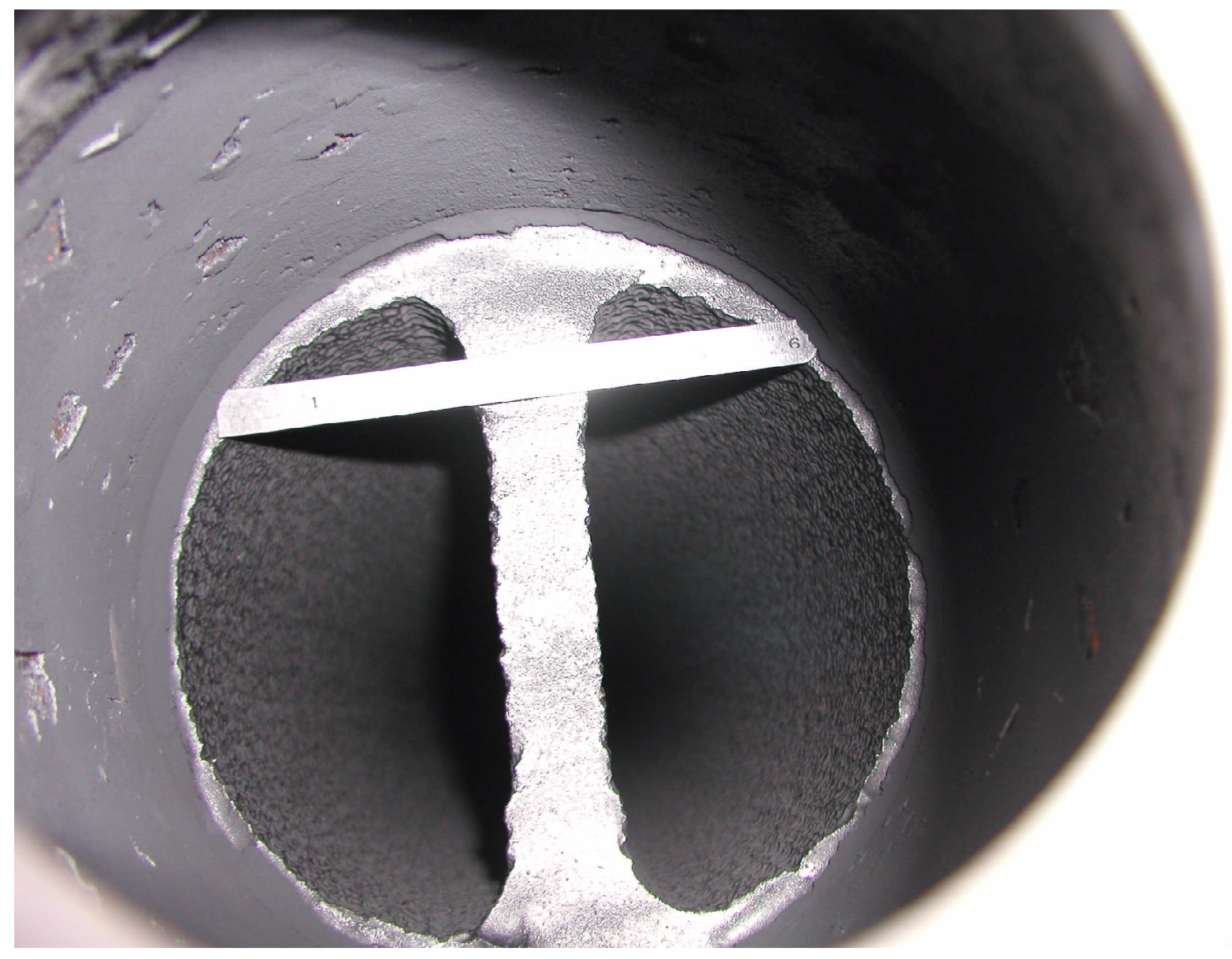

Figure 7 - The HTT-02 Post Test fuel grain as viewed through the nozzle 


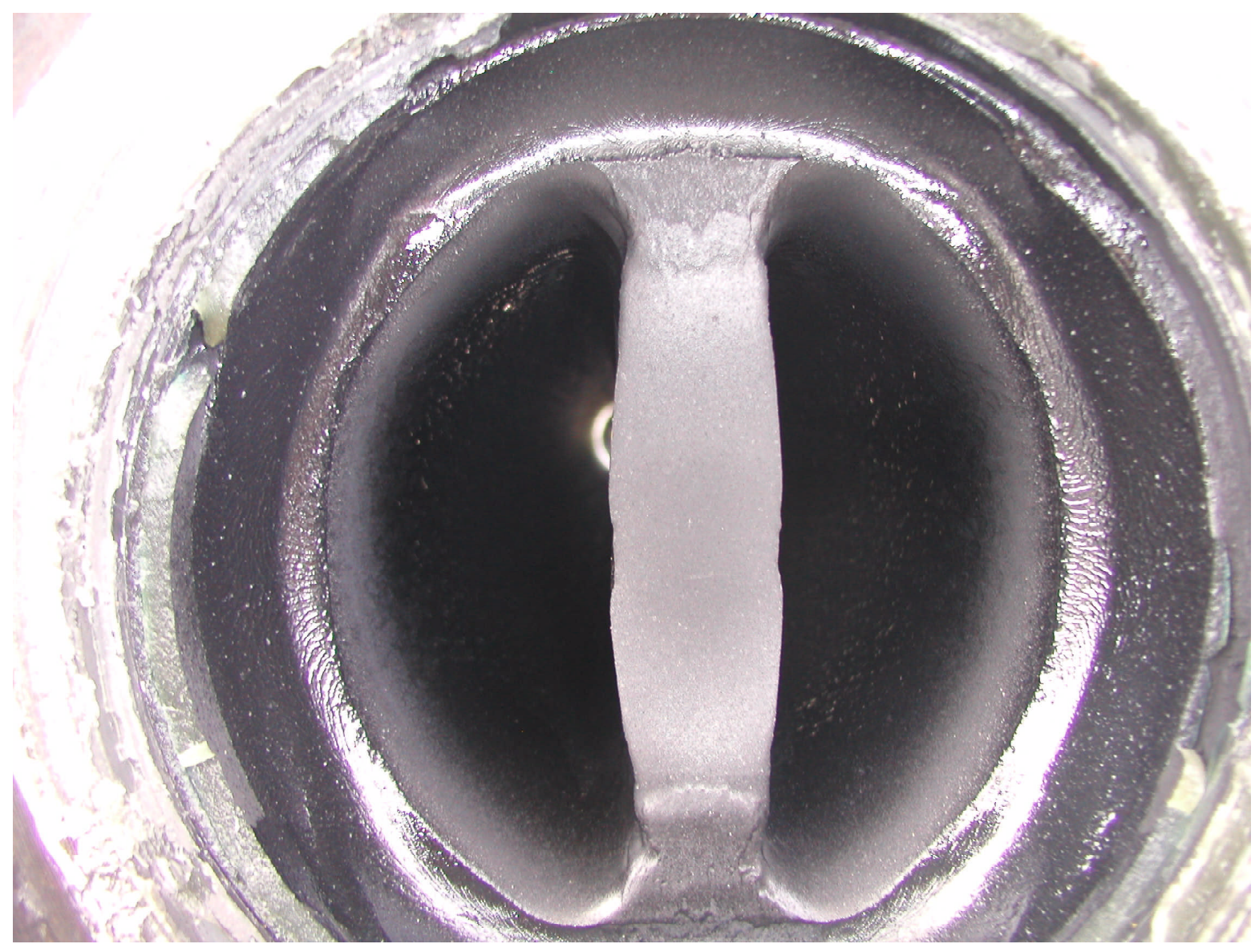

Figure 8 - The HTT-02 Post Test fuel grain as through the head end 


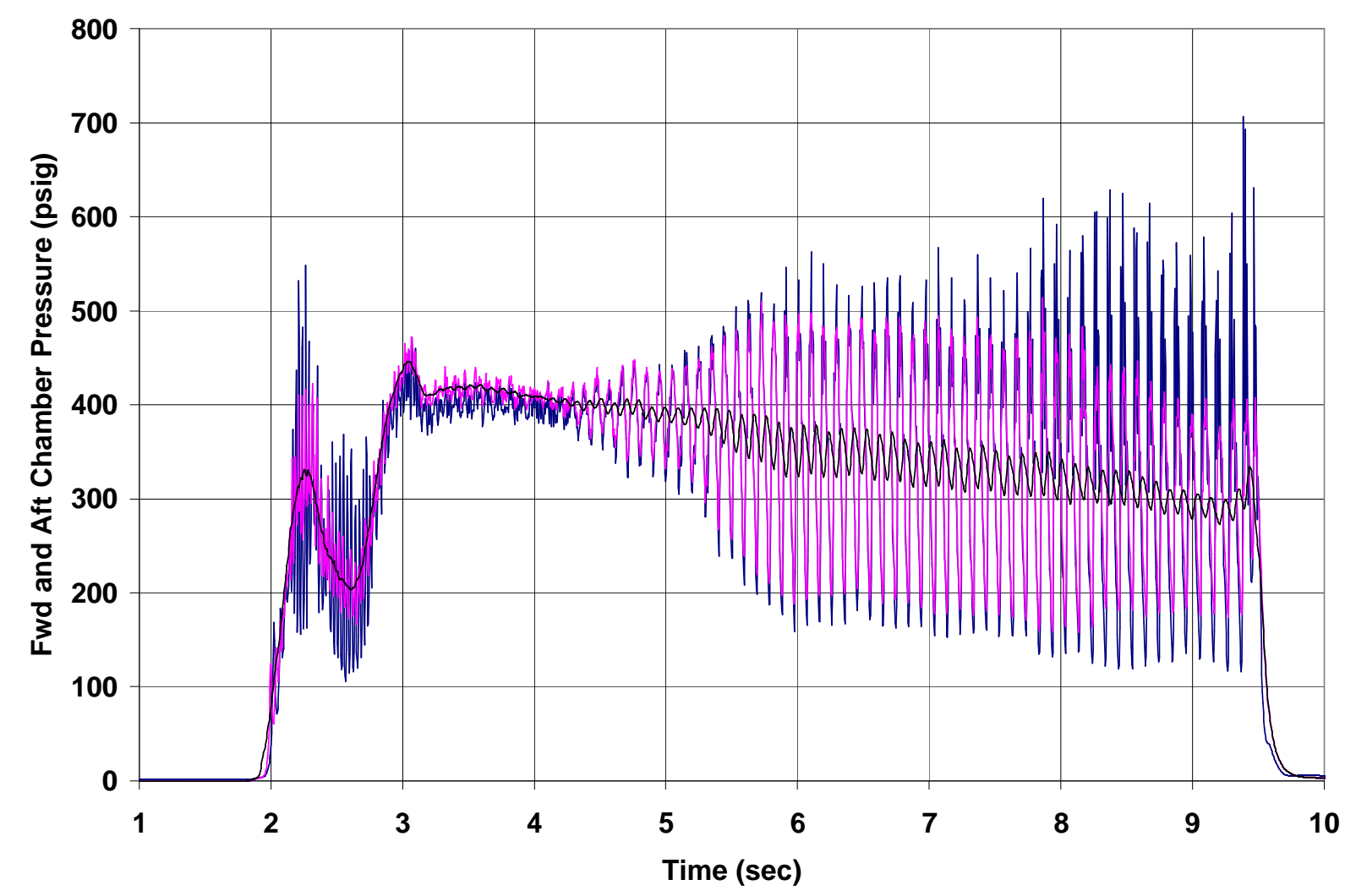

Figure 9 - The HTT-02 Chamber pressure plot

\section{E. Test 3}

The HTT- 03 was a continuation of the second test using the same partially expended fuel grain from HTT- 02 . That test demonstrated the potential for multiple burns, restarting a hybrid motor with this fuel and would establish the total available burn time for this fuel grain geometry and LO2 flow combination. The partially burned fuel grain lit properly and burned at the expected thrust and pressure levels. The chamber pressure began to oscillate mid-way into the burn. The pressure oscillation coupled back into the feed system and was evident in the venturi inlet pressure, ref. figure 10. After the firing the fuel grain was inspected. The analysis predicted the web would get thin and then fail prior to shutdown. It appears that the web failed at a thickness of about three sixteenths of an inch. This data indicates that multi-port hybrid motors with high strength fuel are capable of burning out to an acceptable level of unusable propellant.

American Institute of Aeronautics and Astronautics 


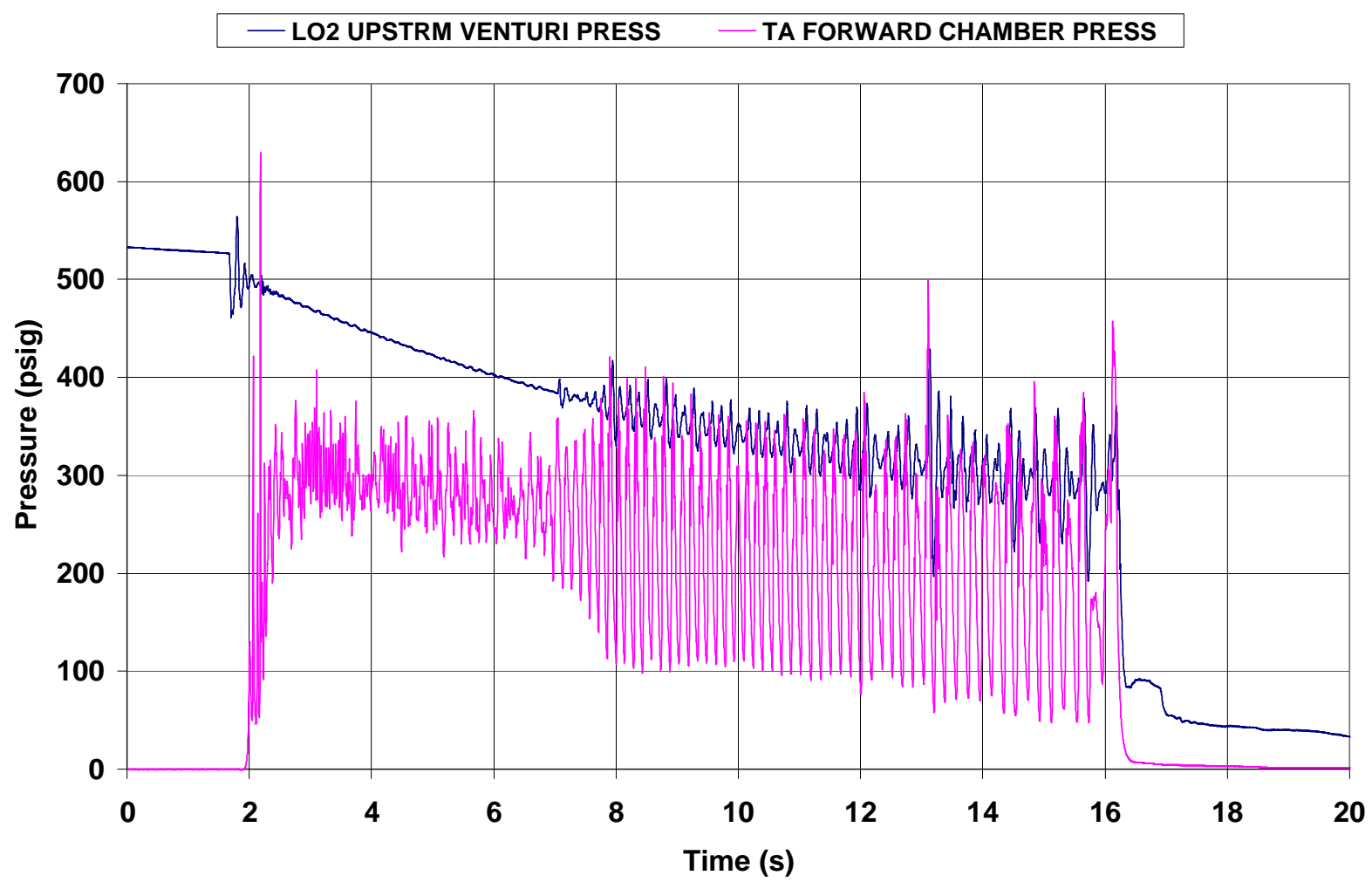

Figure 10 - The HTT-03 Venturi and chamber pressure comparison 


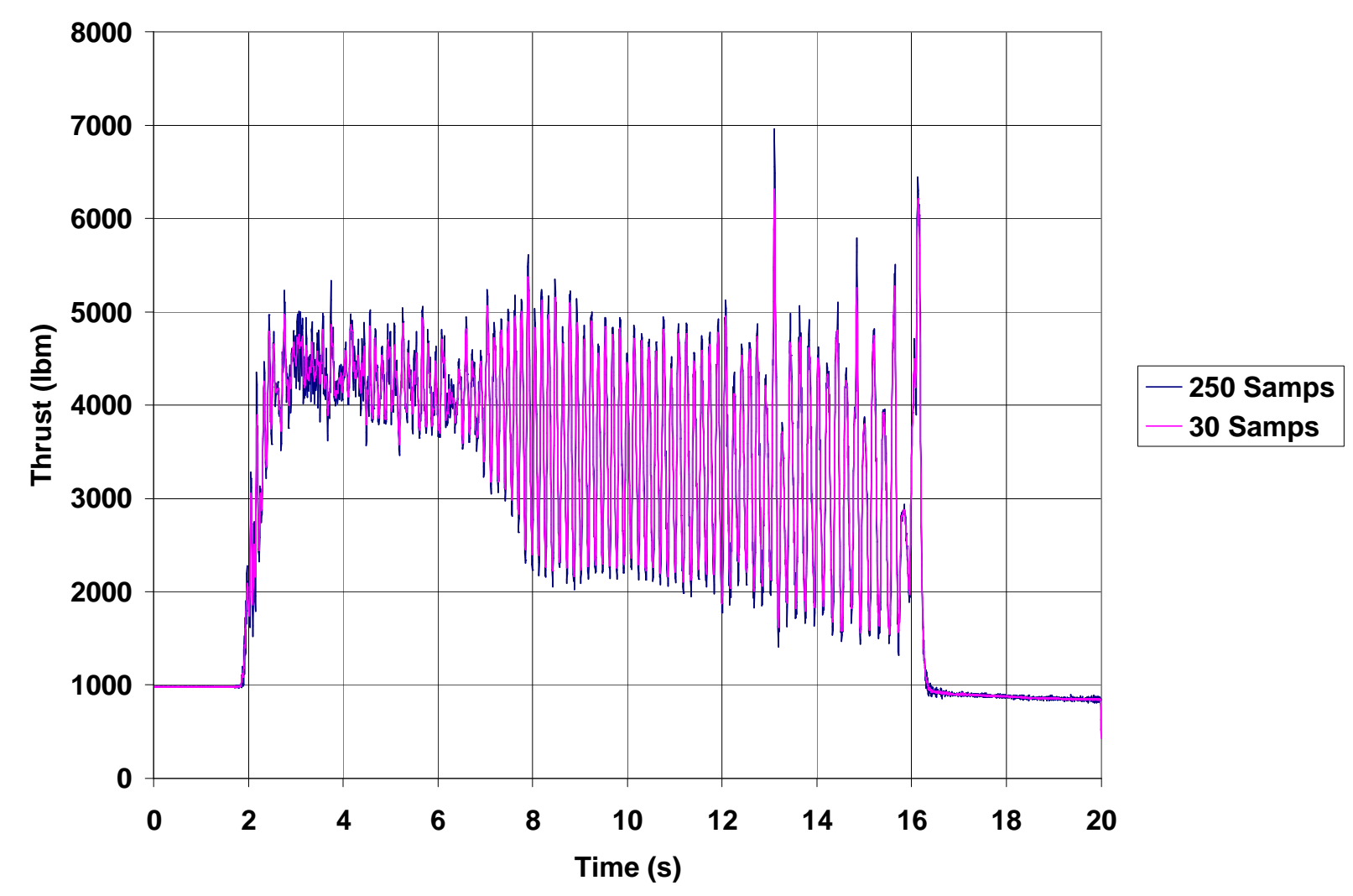

Figure 11 - The HTT-03 Thrust Plot
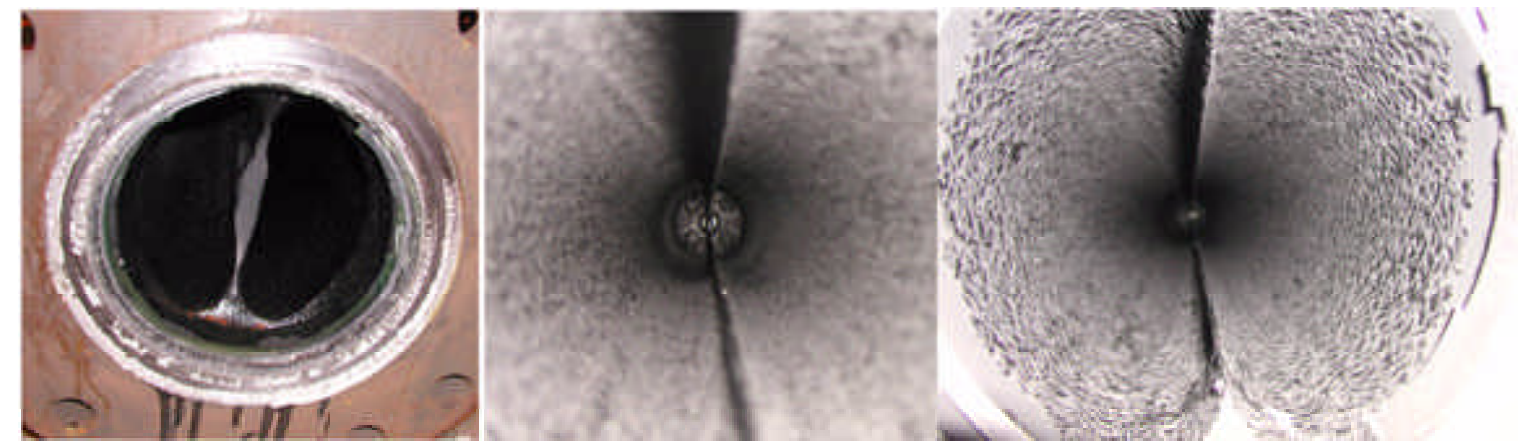

Figure 12 - The HTT-03 multiple Post Test fuel grain shots from various positions

\section{F. Summary}

Three HTTP test firings were successfully executed at Stennis Space Center. These tests demonstrated the superior structural integrity of multi-port hybrid rocket motor fuel grains fabricated with a new high strength HTPB fuel formulation under extreme test conditions. 